Nathaniel W. Yang, MD

Department of Otorhinolaryngology College of Medicine - Philippine General Hospital University of the Philippines Manila

Philippine National Ear Institute National Institutes of Health

University of the Philippines Manila

Department of Otorhinolaryngology Head and Neck Surgery

Far Eastern University-Nicanor Reyes Memorial Foundation Medical Center
Correspondence: Nathaniel W. Yang, MD Department of Otorhinolaryngology Ward 10, Philippine General Hospita Taft Avenue, Ermita, Manila 1000 Philippines

Phone: (632) 5264360

Fax: (632) 5255444

Email: nwyang@gmx.net

Reprints will not be available from the author.

\section{Cystic Cochleovestibular Malformation (Incomplete Partition Type 1)}

A 5-year-old female with bilateral profound hearing loss underwent computerized tomographic imaging of the temporal bone as part of the work-up to determine the etiology of her deafness and to delineate middle and inner ear anatomy prior to cochlear implantation. The examination revealed an inner ear malformation which based on the newest classification of cochleovestibular malformations by Sennaroglu and Saatci, is called an incomplete partition type I (IP-1) or cystic cochleovestibular malformation. This condition is characterized by: (1) a cochlea that is lacking the entire modiolus and cribriform area resulting in a cystic appearance; and (2) a large cystic vestibule. ${ }^{1}$

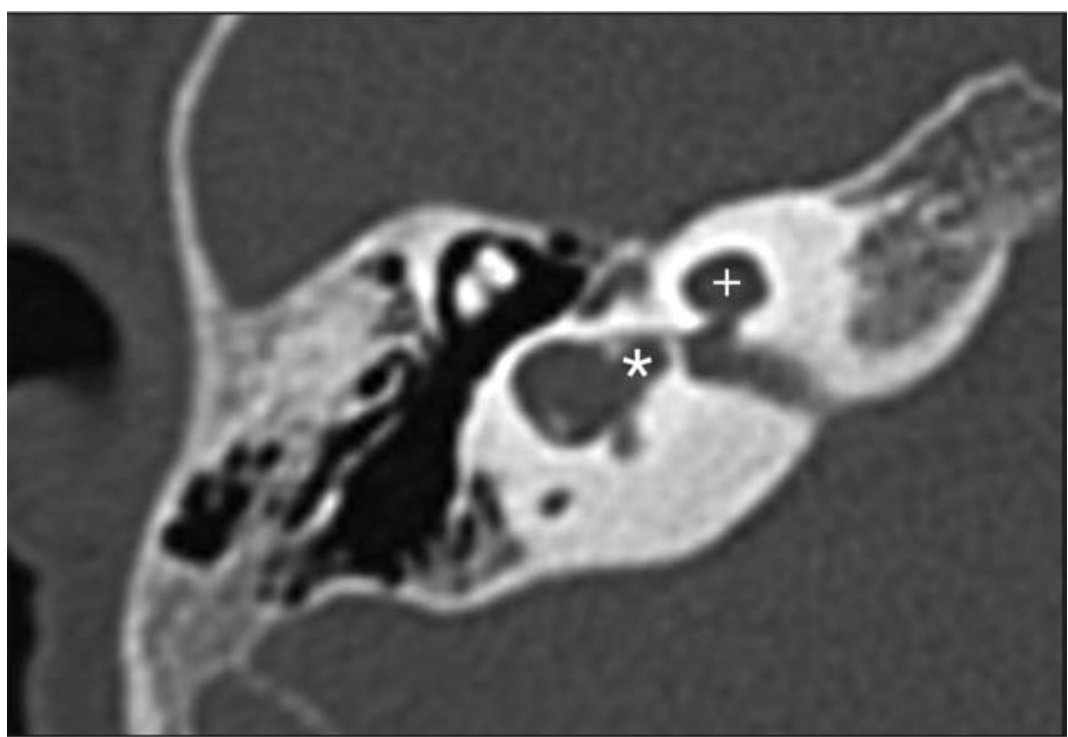

Figure 1. Axial view of the abnormal inner ear showing the cystic cochlea $(+)$ and the cystic vestibule $\left(^{*}\right.$ without the central bony island usually found in the horizontal semicircular canal. 


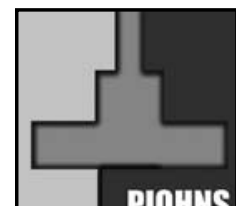

FROM THE VIEWBOX

Philippine Journal Of Otolaryngology-Head And Neck Surgery

Vol. 25 No. 1 JANUARY - JunE 2010

PJOHLS

Temporal bone imaging is among the most useful examinations in the etiological investigation of idiopathic sensorineural hearing loss in children, with up to $30 \%{ }^{2}$ of the imaging studies showing an abnormality. The detection of inner ear malformations is important as some abnormalities are associated with an increased risk of meningitis or progressive hearing loss following head trauma. ${ }^{3}$ Likewise, the approach to cochlear implantation may be influenced by the type of malformation. In this particular patient, the use of a cochlear implant with a full-band electrode design may be more appropriate, as the location of the neural elements within the cystic cochlea is not definitely known.

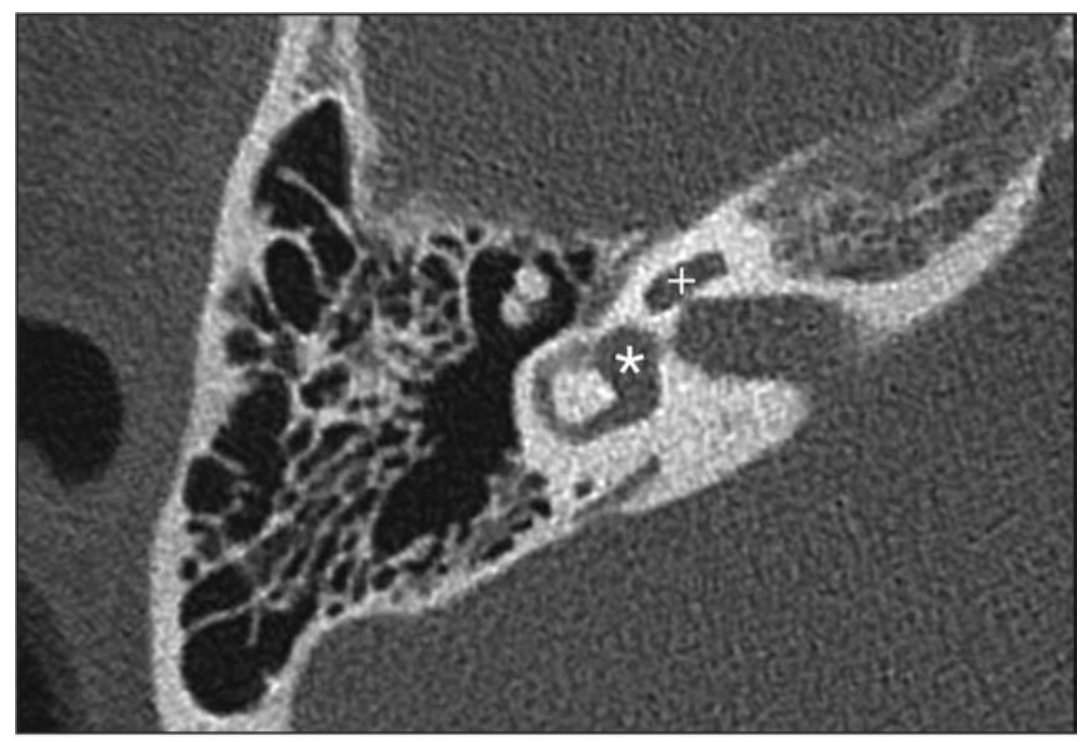

Figure 2. Axial view of a normal inner ear at the same level as Figure 1, showing the "signet ring" configuration of the horizontal semicircular canal and vestibule $\left(^{*}\right)$ and the first turn of the cochlea (+).

1. Sennaroglu L, Saatci I. A new classification for cochleovestibular malformations. Laryngoscope 2002; 112: 2230-2241.

2. Preciado DA, Lawson L, Maden C, et al. Improved diagnostic effectiveness with a sequential diagnostic paradigm in idiopathic pediatric sensorineural hearing loss. Otology \& Neurotology 2005; 26: 610-615.

3. Park AH, Kou B, Hotaling A, et al. Clinical course of pediatric congenital inner ear malformations. Laryngoscope 2000; 110: 1715-1719. 